\title{
Liberalism and Societal Integration: In Defence of Reciprocity and Constructive Pluralism
}

\author{
Dora Kostakopoulou
}

'The same rivers are constituted by the regular flow patterns of different and different waters which scatter and gather (...) come together and flow away (...) approach and depart.'

(Heraclitus, Fragment 214)

\section{Introduction}

Society is a nexus consisting of mutual relationships and co-operative interactions among individuals for the purpose of maximizing collective welfare. ${ }^{1}$ Aristotle captured this eloquently: 'the city comes into existence in order that men may live; it persists that they may live well.'2 Human interactions and participation in practices of reflexive cooperation create connections and interacting networks of power which, in turn, determine what participants should expect from others and from the institutional designs regulating societal contribution and distribution and the principles underpinning them. All societies are premised on the existence of a relative symmetry between contribution and distribution, since the former creates the conditions of possibility for the latter, as well as on a membership scheme which transforms individuals into members of a bigger collective whole.

Because contemporary polities define themselves as nation-states, the right to participate effectively in the common regulation of the public affairs on equal and fair terms and to have an equal right to the enjoyment of the goods of the commonwealth does not extend to all contributors. The prevailing nationality model of citizenship ensures that official partners in the collective endeavour are only the nationals and those who are willing to 'integrate' into the society and to become like nationals via naturalization. In this article, I reflect on this institutional deficit by critically examining the notion of societal integration and, more particularly, by taking issue with integration tests as prerequisites to naturalization. I argue that this established institutional grammar should not prevent us from exposing the principle of national reciprocity to a democratic critique (section 2) and from widening and deepening reciprocity (section 3 ). In fact, democratic imaginations and institutionalized ways of living together could benefit from calling into question national reciprocity. My argument for its replacement with comprehensive reciprocity and the transformation of the latter into an organ-

1 Alfred North Whitehead, Adventures of Ideas (New York: Macmillan, 1967).

2 Aristotle, Politics, I, 1, 1252 b12. 
izing principle of political life in liberal democracies is contained in the final section of the article.

\section{On the wrong side of collaboration: societal integration and mandatory testing}

Although liberalism is not a unified doctrine but an axis around which many variants of it coalesce, it is, nevertheless, true that it is premised on the principle of equal human dignity. Liberals of all persuasions adhere to the belief that individuals deserve equal concern and respect. ${ }^{3}$ They are thus entitled to be treated as equals not because they belong to the same class, caste, race, gender or nationality, but because they have the same moral personality irrespective of their class, caste, race, gender or nationality. A second distinguishing characteristic of liberalism is its emphasis on individuality and self-development. This explains its aversion to political despotism, state authoritarianism and to unnecessary interferences with individuals' lives so as to impede their self-development. ${ }^{4}$ In other words, its underlying philosophy is the philosophy of live-and-let-live as opposed to the philosophy of live-and-don't-let-live or live-as-commanded by the ruling elite(s).

The abstract liberal analytical framework does not always reflect socio-political realities. This is not only because abstract theories more often than not cannot account for the peculiarities of political relations and the correlational qualities of events. It is also due to the fact that, although liberal norms are attuned to principled considerations and overriding reasons of public interest, socio-political systems have been built on human beings' exploitation. The latter term captures domination, unequal treatment, the stigmatization of certain individuals and groups and the consistent devaluation of their contributions as well as abuses of dominant positions, be they on the part of the state or of majorities of all sorts. Ortega y Gasset once commented that liberalism is the 'supreme act of generosity,' since by conceding rights to a minority, the majority 'announces the determination to share existence with the enemy; more than that, with an enemy that is weak. ${ }^{5}$ In reality, however, it is not generosity that underpins the grant of minority rights, but reciprocity, since majority positions are transient. Majorities today will be minorities tomorrow, and members of majorities may be simultaneously members of minorities with respect to another issue or characteristic. In other words, there exist fluidity and a regular exchange of majority and minority positions.

3 Ronald Dworkin, A Matter of Principle (Cambridge, MA: Harvard University Press, 1985).

4 John Locke, A Letter on Toleration in Second Treatise on Government, ed. J.W. Gough (Oxford: Blackwell, 1956); John Stuart Mill, On Liberty (Harmondsworth, UK: Penguin Books, 1987); L.T. Hobhouse, Liberalism (New York: Oxford University Press, 1964; first published 1911); John Dewey, Individualism Old and New (Carbondale: Southern Illinois University Press, 1984 [1931]). José Ortega y Gasset, The Revolt of the Masses (New York: W.W. Norton, 1957 [1929]), 76. 
What has made, and makes, liberalism, as defined above, compatible with illiberal sociopolitical realities and indifferent to the fluidity of majority/minority positions is the use of a political vocabulary containing terms such as 'societal existence,' 'survival,' 'adaptation,' 'adjustment' and 'maladjustment,' 'assimilation,' and 'integration.' All these terms are supposed to aid associated life. In reality, however, they are used as vehicles for introducing hidden evaluations and agendas. All of them serve to frame underprivileged and discriminated against individuals or groups as problems, to place them in opposition to society in general and then to require their 'adjustment' or 'assimilation' or 'integration' into it. In other words, instead of societies reflecting on structural inequalities, prejudices and seeking to 'let people fully in' and to recognize them as valued collaborators, they depict them as threats to societal unity, cohesion or integration. Individuals and groups are seen to bear societal 'demerit badges' and to require education and conformity to the culture, beliefs, values and ways of life of the dominant societal group or the majority.

In The Sociological Imagination, Charles Wright Mills commented critically on the biological roots of the concept of adjustment and particularized his analysis by referring to the so-called immigrant problem. ${ }^{6}$ Of course, the twentieth century was ridden with 'problems' and the explicit denial of reciprocity: the 'Jewish problem,' the 'N... problem,' the 'women problem,' 'the anarchist problem,' 'the poor problem,' the 'Roma problem,' the 'gay problem' and so on. And all these alleged 'problems' were based on biases, the 'othering' of social collaborators and on their depiction as deficient on one or more grounds in comparison with the selected, or dominant, group(s) and therefore the reinforcement of their subordinate status. ${ }^{7}$ Instead of projecting a forward-starched perspective, removing obstacles to the creation of mutually beneficial relations and enlisting people to participate in society, narratives on societal adjustment or integration look backward, that is, seek to legitimate people's already constructed outgroup, and always inferior, status. To put it differently, integration narratives and policies focus on the wrong side of collaboration. Instead of making contribution to society the relevant criterion, they focus on the differences-cum-deficiencies of individuals and groups and on how much 'difference' a society can contain without losing its unity or cohesion or identity. This focus is chosen arbitrarily; elites look away from what matters and look towards what serves their interests and beliefs. The latter determine what is relevant and important for a society's functioning within a spatio-temporal location. Accordingly, full societal and political memberships are not facts sprung by one's co-existence and interaction with others; they are viewed to be privileges that are reserved for deserving members.

6 Charles Wright Mills, The Sociological Imagination (Oxford: Oxford University Press, 1959), ch. 4.

7 See, inter alia, Ricky van Oers, Eva Erboll \& Dora Kostakopoulou (eds.), A Redefinition of Belonging? Language and Integration Tests in Europe (The Hague: Brill/Martinus Nijhoff, 2010); Floya Anthias \& Mojca Panic (eds.), Contesting Integration, Engendering Migration (Houndmills: Palgrave, 2014). 
Migrants have been particularly vulnerable to processes of othering. Throughout the twentieth century their different languages, cultures, accents, beliefs, traditions have been depicted as reasons for their alleged deficiencies and, in turn, rationales for their 're-education' into the language, customs, history, constitution and the values of Western host states. Because societies defined themselves as national societies and national homogeneity was seen to be a precondition for unity and a well-functioning democracy, differences had to be eradicated and amalgamated, assimilated (1920s-1960s) and integrated (since the late 1960s). The latter policy framework required migrants to accept the public norms and values of the host society while allowing space for the retention of cultural differences in the private domain. In addition, throughout the twentieth century mandatory testing of the aspiring citizens has been used in order to demonstrate their 'fitness' for citizenship. ${ }^{8}$ Literacy tests, language tests, dictation tests and knowledge of the constitution tests have served as 'good citizenship' filters in the US and elsewhere.

The new millennium witnessed the revival of the integration discourse and mandatory testing in Europe. The Netherlands took the lead on the displacement of the multiculturalist paradigm by enacting the 1998 Newcomer Integration Act which required newcomers to attend language and 'social orientation' courses. The UK followed the same path by enacting the Nationality, Immigration and Asylum Act 2002 which tightened naturalization requirements by introducing the requirement of knowledge of 'Life in the UK' test and formalising the linguistic requirement. Since then, other European countries, such as Austria, Germany, Denmark, Hungary and so on, raised the level of knowledge required for eligibility for naturalization, adopted compulsory oral and written tests requiring increasing levels of linguistic competence and familiarity with issues relating to national politics, history, geography, rights and customs. Although official justifications of integration testing in the domain of naturalization emphasize its facilitative role in the new citizens' insertion into host societies, most scholars agree that it has restricted access to nationality and has prolonged migrants' exclusion from full participation.

The requirements of reciprocity have been sidestepped. On the one hand, when newcomers are called upon to share the burden of the commonwealth, neither their nationality nor their newcomer status are relevant considerations. States treat them as equal burden sharers; they need to pay taxes and national insurance contributions and to respect the law. They are not placed on a graduated taxation scheme based on the duration of their residence. ${ }^{9}$ Nor are they given a settlement allowance, such as the one given to new members of corporations and other organizations. Instead, they are expected to contribute to the commonwealth in

8 I have reflected on it in 'The Anatomy of Civic Integration,' Modern Law Review 73(6) (2010): 933-58.

9 I draw here on my reflections in 'What Liberalism is Committed to and Why Current Citizenship Policies Fail This Test,' in 'How Liberal are Citizenship Tests?,' ed. R. Baubock \& C. Joppke, EUI Working Paper, RSCAS 2010/41, EUI. 
the same way as anybody else. And yet, when it comes to the enjoyment of the benefits of membership, including the right to be treated as a full and equal member of the society, long-term resident migrants are caught in graduated schemes of membership and unequal statuses because of their 'alien' nationality. Their equal burden-sharing status, their law abidingness and their prolonged residence are not sufficient for citizenship acquisition. Equal burden sharers are thus deemed to be unworthy or undeserving of a full and equal beneficiary status. States treat them as equals and fully integrated into society when it comes to the extraction of their resources, and as unequals, who must fulfil integration requirements, when it comes to the enjoyment of societal benefits. They need to 'earn' their entitlement to citizenship and to demonstrate that they are 'safe' and 'good' citizens.

It might be objected, here, that restrictive naturalization is an unfortunate consequence of the pursuit of a liberal, and very legitimate, end; namely, the need to ensure the unity and social cohesion of plural communities. But such an argument overlooks both the historical pedigree of civic integration and mandatory testing as well as the fact that integration is a problematic concept. What is the meaning of integration, after all, and how can one measure as to whether it has been achieved? Are nationals and naturalized persons integrated enough so as to display a conformist attitude towards policies and ways of doing things and an acceptance of all the qualities governments associate with good citizenship, including economic self-sufficiency? Arguably, 'integration' is a long term and multifaceted process for both the existing population and new members which cannot be subsumed under a contract of one or two or even five years' duration. For both groups, it may be bumpy and segmented, ${ }^{10}$ that is, closely linked to time and structural conditions, but it is equally true that it can be nurtured by the right policies and institutional conditions. ${ }^{11}$ If people experience societal rejection, they will not try to 'integrate'; they may feel 'more comfortable remaining outsiders. ${ }^{12}$ More importantly, even if we concede that it can be been achieved, it can easily be punctuated by the spread of a sense of disillusionment and by dissent.

Besides the ends of integration, the means devised by European governmental elites result in pushing integration programmes beyond the scope of liberal reciprocity. Official discourses often stress the existence of a contract between the

10 On bumpy-line assimilation see Herbert J. Gans, 'Comment: Ethnic Invention and Acculturation: A Bumpy-line Approach,' Journal of American Ethnic History 11 (1992): 42-52. On segmented assimilation see Min Zhou, 'Segmented Assimilation: Issues, Controversies, and Recent Research on the New Second Generation,' in The Handbook of International Migration, ed. Charles Hirschman, Philip Kasinitz \& Josh DeWind (New York: Russell Sage Foundation, 1999), 196-212.

11 Joseph Carens has observed that 'we cannot simply take as unproblematic the notion that we can measure the success of integration of immigrants against the standard of proportional sharing in whatever the majority has and does'; Joseph H. Carens, 'The Integration of Immigrants,' Journal of Moral Philosophy 2 (2005): 42.

12 George A. Akerlof \& Rachael E. Kranton, Identity Economics: How Our Identities Shape Our Work, Wages and Well-Being (Princeton: Princeton University Press, 2010), 102-3. 
host society and the new members and the existence of complementary expectations, despite the facts that the latter do not have the option of disregarding integration requirements, cannot engage in dialogue with the relevant authorities about their content and cannot contest the 'contractual' terms. Migrants' subjection to the disciplinary power of the state, coupled with the mandatory, sanctions-oriented character of integration tests, show that the aim of citizenship tests is not to enhance citizenship capacity and the free and unimpeded development of the self in manifold associations with others. ${ }^{13}$ Instead, they are designed to enhance governmental control in the domain of citizenship acquisition and the disciplining of the migrant population under the shadow of the increasing influence of right-wing parties in Europe. ${ }^{14}$ Their problematic nature is further accentuated by the fact that they can also apply selectively; in the Netherlands, for example, citizens of Japan, Australia, New Zealand and the USA are deemed to be 'assimilable' and are thus exempt from them. All these considerations give rise to a deeper question about the (rightful) place of reciprocity in contemporary liberal democratic polities.

\section{Interlude: a change of the membership criterion}

Geertz has correctly pointed out that more often than not the criteria for membership are not decided by a society's existing members; instead, they are assumed. ${ }^{15}$ This is largely because existing members find themselves thrown into a society whose boundaries and membership circles have been fixed by previous members, or to be more precise, the previous governing elites. This, of course, does not mean that they are inflexible. ${ }^{16}$ Indeed, a major occasion for the transformation of societies and political systems has been the reconsideration of who is to be included into polity and who is to be excluded, as Akerloff and Kranton have noted in another context. ${ }^{17}$ Several candidates for determining the rules of membership have been tried, practised and subsequently criticized for their oppressive effects. These could be subsumed under the more abstract categories of (a) ascription and thus the sharing of some thick or 'thickish' communal characteristics, (b) consent and the associated assumption of a privilege granted by the consenter and (c) being a 'demotes,' that is, an inhabitant of a community and a participant in reciprocal exchanges. According to the latter more pragmatic cri-

John Dewey, The Public and Its Problems (New York: H. Holt, 1927), 150.

Ricky van Oers, 'Citizenship Tests in the Netherlands, Germany and the UK,' in A Redefinition of Belonging? Language and Integration Tests in Europe, ed. Ricky van Oers, Eva Erbøll \& Theodora Kostakopoulou (The Hague: Brill Publishers/Martinus Nijhoff, 2010); Bernhard Perchinig, 'All You Need to Know to Become an Austrian: Naturalisation Policy and Citizenship Testing in Austria,' in A Redefinition of Belonging? Language and Integration Tests in Europe, ed. Ricky van Oers, Eva Erbøll \& Theodora Kostakopoulou (The Hague: Brill Publishers/Martinus Nijhoff, 2010).

Clifford Geertz, The Interpretation of Cultures: Selected Essays (New York: Basic Books, 1973).

On this, see also Hannah Arendt, The Human Condition (Chicago: Chicago University Press, 1958).

17 Akerlof \& Kranton, Identity Economics. 
terion, membership reflects tangible actions and interactions and not attributesin-common.

Ascription prioritizes some characteristics which are deemed to be essential to the formation and continuity of communities, such as a common ancestry, ties of history, a common culture, a shared ethnic origin, the worshipping of the same god(s), subjection to the same royal sovereign, rootedness into the soil and so on. In other words, narratives based on ascription invoke what may be termed a kernel theory of community; the kernel contains all the essential qualities, the basic characteristics that define community, membership and sustain the ties that bind the members together. Because membership reflects attributes or characteristics, it presumes the absence of the questioning of the status quo as well as the bracketing of the structurally differentiated positions of the members. In fact, the latter are seen to be structurally equivalent to one another. In addition, because kernels need shells, ${ }^{18}$ ascriptive narratives of membership are bound to lead to the exclusion of all those elements, and individuals, which deviate from the enduring qualities contained in the kernel.

Consent, on the other hand, appears to be a more rational and less exclusionary criterion of membership. This is because it makes membership a matter of a community's consent, instead of requiring the sharing of a common 'substance.' New members can request admission which can be granted by a community and this is nothing else than a manifestation of democratic self-determination. The problem with consent, and indeed the problem with the Lockean-inspired contractarian thinking, is that it is just a thought experiment. In reality, the communities consenting on an individual's membership are national communities, endowed with allegedly enduring qualities, having predefined borders, citizenship laws and specific migration policies. ${ }^{19}$ Hence, ascriptive rules are always camouflaged by, and operate under, the seemingly neutral criterion of consent.

The third criterion, that is, domicile, is more pragmatic and process oriented. It regards one's enmeshment into a cooperative nexus and involvement in socioeconomic activities as a necessary as well as sufficient rationale for political membership and citizenship status. On this reasoning, the characteristics associated with the kernel theory of community are nothing else than expressions of stationary equilibria and ideological assumptions in so far as they bracket the de facto volume and extent of ordinary socio-economic activity in which individuals

18 Cf, here, Michael Walzer, Spheres of Justice: A Defence of Pluralism and Equality (New York: Basic Books, 1983); David Miller, On Nationality (Oxford: Oxford University Press, 1993).

19 The same criticism can be directed towards John Rawls's notion of reciprocity since it takes place within the bounds of liberal national communities. For a critical reflection, see Theodora Kostakopoulou, 'Thick, Thin and Thinner Patriotism: Is This All There Is?,' Oxford Journal of Legal Studies 26 (2006), 73-106. 
are involved. ${ }^{20}$ Official discourses and governmental elites presume that there exists a negative correlation between heterogeneity, be it national, ethnic, religious, linguistic, cultural and so on, and collective action. This is seen to justify in-group favouritism and suspicion and hostility towards outsiders. Societal participants, or to be more specific, the preferred societal participants, are seen as co-nationals or co-ethnics, and not as co-operators. Accordingly, the norm of reciprocity animating collective action has been in the main confined to co-national or co-ethnic reciprocity.

The belief in co-national reciprocity conceals what 'goes on in reality.' Communal life does not exist, and continues to evolve, because it is centred on a kernel (or a substance) or because participants either have feelings for each other or are guided by the same beliefs or hold similar values. It does so in a spontaneous way because collective action makes human living worthwhile and individuals have an interest in cooperation. Accordingly, the sites on which associated life unfolds are receptacles of people. National states are multinational, multiethnic, mutlireligious, multilingual, multiracial etc., and one can easily trace what Dewey called more than one hundred years ago 'the growth in comprehensiveness,' that is, 'the widening of social consciousness - of the range of persons whose interests have to be taken into account in action' throughout history. ${ }^{21}$ Ortega y Gasset also commented that 'the state is neither consanguinity, nor linguistic unity, nor territorial unity, nor proximity of habitation. It is nothing material, inert, fixed and limited. It is pure dynamism - the will to do something in common' and, 'the state's unity consists precisely in superseding any given unity. ${ }^{22}$ Arguing otherwise would raise legitimate questions about individuals' self-deception or intent to manipulate others.

Indeed, every act by an individual initiates a new connection and leaves a seed for a new flow of activity and for further involvement, thereby furnishing the ties that bind participants in a certain societal nexus together. The societal nexus emplaces the connections among participants and their reciprocal exchanges which are continuously unfolding. This process view of community based on relations of interdependence allows for extensive and flexible membership with a view to nurturing mutually productive communities of relationships. On this view, reciprocity is societal or comprehensive - and not co-national or co-ethnic,

20 Jon Elster argues that envy, opportunism, codes of honour or the ability to make credible threats and promises could be taken to provide the 'cement of society'; Jon Elster, The Cement of Society: A Study of Social Order (Cambridge: Cambridge University Press, 1989), 250-1. But cf., James C. Scott, 'Geographies of Trust, Geographies of Hierarchy,' in Democracy and Trust, ed. Mark E. Warren (Cambridge: Cambridge University Press, 1999), 273-89. Compare also Hannah Arendt's argument that 'the community comes into being through equalising, isasthenai'; Hannah Arendt, 'Philosophy and Politics,' Social Research 57 (1990): 83, cited in Hans Lindahl, Fault Lines of Globalisation (Oxford: Oxford University Press, 2013), 238. In it, Lindahl provides an excellent account of reciprocity and its relation to boundary setting; see ch. 7 .

21 John Dewey, Outlines of a Critical Theory of Ethics (New York: Greenwood Press, 1969 [1891]), 210.

22 Ortega y Gasset, The Revolt of the Masses, 162-3. 
because political communities are not communions. By the latter, I mean that they do not depend on characteristics and commonalities, such as a shared nationality, religion, language and culture, that is, all the elements associated with an already defined status of (national) being. They rely, instead, on living realities associated with 'doing' and 'participating' and, as Dewey has noted, 'genuine individuality is intimately connected with the social conditions under which they associate with one another. ${ }^{23}$

People are together in cooperation and in respectful symbiosis even when discourses in the public domain disseminate narratives about being together in a common national identity or in security (see section 4 below). Ideas projected by the dominant elites are falsely regarded as lodged in community relations because, like religion, it is the function of nationalist ideology to do so. Accordingly, new members need a process of initiation into the unique ways of life, values and characteristics of a nation which allegedly they cannot easily understand and cherish and their subsequent voluntary adherence to them in order to be formally admitted to the body politic. Yet, as discussed in the previous section, these ideas are worthless when it comes to the realities of activating their employee and taxation statuses. Co-national or co-ethnic reciprocity does not apply to these fields; everybody, irrespective of nationality, ethnic origin, race, religion, class and so on is expected to contribute to the commonwealth.

The prevailing norm of co-national or co-ethnic reciprocity thus prevents the official recognition of the public self within the self, of the citizen in each person participating in the shared experiences of the community and of the societal membership part in each private self. In brief, it makes the co-operative or transactional character of society unworthy of consideration. It also makes human solidarity a utopia in so far as solidarity reflects the temporary suspension of reciprocity and its projection in future time. The frontier of common sense thus shifts as the ruling ideology's misrepresentations gain currency because, to paraphrase Mill, 'like the wall of a city, it has usually been erected, not to be receptacle for such edifices as might afterwards spring up, but to circumscribe an aggregation already in existence. 24

\section{The fallacy of 'societal survival': reciprocity, constructive pluralism and conflict resolution}

I have argued in the foregoing sections that liberalism requires that individuals should be valued and not presumed to be deficient, backward or inferior and that they should be allowed to get on with their lives without having to conform to elites' perceptions of what it means to be a 'good citizen' or a patriot (section 2

23 John Dewey, 'What I Believe, Revised,' in Pragmatism and American Culture, ed. Gail Kennedy (Boston: D.C. Heath, 1950), 32.

24 John Stuart Mill, Essays on Some Unsettled Questions of Political Economy (New York: Cosimo Classics, 2007 [1844]), 99. 
above). The principle of reciprocity necessitates their recognition as actual contributors to the commonwealth and equal contribution carries with it a legitimate claim for their recognition as equal citizens and rightful beneficiaries (section 3 above).

Underlying existing policies and discourses on integration are specific anxieties about 'societies' survival' or the 'maintenance of the stability of the social structure.' Integration is necessary in order to eschew disintegration, adjustment is necessary in order to eschew maladjustment and the ensuing instability or anomie or the breakdown of the social framework. To put it differently, civic or cultural integration ensures that the social structure does not become fragmented or loose and thus likely to fall apart. It is thus often stated that liberal states have room only for liberal citizens and, hence, questions have to be raised about both countries' 'integration capacities' and individuals' 'integration capabilities.' 25 On reflection, however, it is easy to discern that such conceptions are nothing else than narratives of legitimation of political control and of restrictive migration policies. It is simply presumed that the social fabric is held together by virtue of certain values, beliefs, ways of doing things and cultural symbols, and that when the latter are called into question the whole structure weakens. Furthermore, it is presumed that these values, beliefs, ways of doing things and cultural commonalities form a unified structure to which all existing members conform. Moreover, newcomers and their beliefs, value-orientations, cultural sensibilities and so on are presumed to be radically different from, and simultaneously antagonistic to, the assumed domestic normative structure. In this way, instability is introduced into a 'harmonious society' from the outside. But all these are just presumptions which may be effective in legitimating certain political relations but inaccurate in reflecting contemporary realities.

Not only do such presumptions hide the role of economic, political and legal institutions in making societies what they are, but they also bracket the webs of human interactions and reciprocal exchanges which create the 'unity' of society. Wright Mills exposed the ideological role of what he called 'legitimations' and the Parsonian schema of value patterns or the shared values of a normative structure. ${ }^{26}$ And more recently, Scheffler commented on the fallacies of believing that 'each individual has a single, well-defined culture' and that immigration threatens countries' national cultures. ${ }^{27}$ The 'societal survival' narrative also brings into the public discourse an illiberal and anti-democratic thinking by negating reciprocal exchanges among people and the productive energies generated by 'difference(s).' As such, it bears more than a 'family resemblance' with political ed by the European Council on 16 October 2008.

26 Wright Mills, The Sociological Imagination, $36 \mathrm{ff}$.

27 Samuel Scheffler, 'Immigration and the Significance of Culture,' Philosophy and Public Affairs 35(2) (2007): 93-125. Scheffler's defence of cultural fluidity and change, which he calls Heraclitean pluralism, accommodates 'a reasonable cultural preservationism' which resists unwanted changes and preserves traditional practices; see $107 \mathrm{ff}$. 
discourses creating enemies and using fear in games of political manipulation. In his 'Zum Begriff der politischen Freiheit,' Franz Neumann pronounced the latter as active constituents of illiberal politics. ${ }^{28}$ The depiction of certain groups as a threat to the continuity or the unity of society appeals to governing elites because almost anything can be constructed to be a threat to the survival of society. But 'survival' is always a vague concept; on closer inspection, it is difficult to understand why something should threaten the survival of a society as opposed to stimulating its growth and further development. In brief, the societal survival narrative denies the reality of phase transition and transformation.

Change or evolution is nothing else than a reconstitution of the previous phase and therefore it could be argued that anything that opens up ways for the development and the regeneration of something could always be resisted on the ground that it threatens the survival of its old form or phase. In this respect, it would be misleading to perceive survival and change as opposite states; instead they are states that slide into each other. Locke used the term supersession to describe this process; everything changes or is 'perpetually perishing' thereby being superseded by something else. And in 1944, Wilmon Henry Sheldon noted the possibility of a substance to remain in a sense permanent even while passing over into or being supplanted by another substance: As he put it, '(...) these processes will be seen to have the incremental character which joins novelty to permanence - retention of the old, undiminished, plus something new, and again, retention of these plus something more of new, and do forth. The permanent contributes to growth, and growth increases the store of permanent things. ${ }^{29}$

In the light of the foregoing insights, societies do not disintegrate or just survive; they evolve, become more complex and interlaced, more differentiated and more structured on multiple levels. Nor do they possess a 'stable equilibrium' status which is threatened by the admission of newcomers. Governmental discourses about 'stable equilibria' conceal the existence of both de facto disequilibria, be they socio-economic or ideological, and de jure 'created equilibria,' that is, ordered and legally enforced arrangements. Instead of survival, it is thus more accurate to refer to processes of change in social relations particularly since the latter ensure the continuity of societies in the long run. Apart from major catastrophes, wars and natural disasters of cataclysmic proportions which can really fracture societies and cause disintegration, societies in Western Europe and elsewhere constantly evolve and the presence of human capital as well as the circulation of new ideas and ways of thinking are opportunities for enrichment, adaptation and growth.

Constructive pluralism recognizes this as well as the fact that conflict is endemic in dynamic processes of change irrespective of the location of its source; it could

This was published in English in 1957 as 'The Democratic and the Authoritarian State: Essays in Political and Legal Theory'; Franz Leopold Neumann, The Democratic and the Authoritarian State: Essays in Political and Legal Theory (London: Free Press, 1957). 
be either internal or external or internal/external. It could be brought about by the different interests, diverse beliefs and disagreements of insiders or the nonyet fully insiders. But it must always be seen in process. It is easy to reify and objectify it - the space can be divided into opposing camps and members can become enemies. By perceiving conflict as a threat resulting in paralysis and disintegration, however, we narrow the means of its resolution. An alternative way of perceiving conflict which is consonant with constructive pluralism is to view it as a call for further deliberation and reflection. Instead of dividing the political space and transforming disagreements and oppositionalities into enmities, the latter approach affirms reciprocal exchanges and seeks to make a community of it. ${ }^{30}$ Herein lies the constructive appeal of this approach: conflict resolution is premised on the presupposition of an underlying, elementary, community of interest. For if the latter did not exist, that is, if there were no underlying interdependence behind every conflict and simply separation and distance prevailed, nobody would take an interest in it and its resolution. Indifference would be the most likely reaction.

Hence, far from being the breakdown of a relation, conflict is the beginning of a more fundamental inquiry into the origins of different interests and views and the possibilities for genuine dialogue and deliberation. It sparks the realisation that 'we can do much more together,' rather than 'we are together in power or domination or enmity.' And, of course, engaging in inquiry and reflection presupposes (comprehensive) reciprocity and the reaching out towards the other for the creation of mutually productive relationships. In his The Political Theory of the Compound Republic, Ostrom explored in depth the possibility of 'methods of inquiry that enable human beings to use exigencies of conflict to explore possibilities and to move toward resolutions. ${ }^{31}$

Community is a dull affair without disagreements, different beliefs, diverse imaginations and conflicts. Its members occupy (and are placed into) different structural positions, have different make ups and inevitably have different views about the common political reality as well as differentiated experiences of it. ${ }^{32}$ But communities can only be dynamic and projective, that is, oriented towards new and better forms of cooperation, if they bring together diverse people in a common, and hopefully more equal, socio-political life and in welfare. And the latter requires not only back-stretched connections, that is, the involvement of conationals and naturalized persons, but also forward-starched connections, that is, the involvement of citizens in waiting. Liberal democratic polities ought to be able to regulate the process of the transition from the latter to the former status

30 See Theodora Kostakopoulou, 'Towards a Theory of Constructive Citizenship in Europe,' Journal of Political Philosophy 4 (1996); Theodora Kostakopoulou, Citizenship, Identity and Immigration in the European Union: Between Past and Future (Manchester: Manchester University Press, 2001): $102 \mathrm{ff}$.

31 Vincent Ostrom, The Political Theory of a Compound Republic: Designing the American Experiment (London: University of Nebraska Press, 1987), 163-4.

32 Kostakopoulou, Citizenship, Identity and Immigration in the European Union, 107. 
better in the twenty-first century and to refrain from misdirecting their efforts and wasting public resources in futile experiments. Above all, they need to free themselves from the shackles of ideology and electoral posturing and to understand the processes and realities of both transitional arrangements - and civic integration is a transition - and community building. The norm of reciprocity should guide both processes and therefore needs to be extended beyond its assigned liberal national limits. Reciprocity can only be a comprehensive norm in democratic societies - and not an eclectic one, that is, either co-national or coethnic or racial. 